\title{
A OUTRA VOLTA DO PARAFUSO: RELAÇÕES TRANSMEDIAIS DE TEXTO E IMAGEM EM HENRY JAMES E CHARLES DEMUTH
}

\section{THE TURN OF THE SCREW: TRANSMEDIAL RELATIONS BETWEEN TEXT AND IMAGE IN HENRY JAMES AND CHARLES DEMUTH}

Sigrid Renaux

RESUMO: A questão da transposição intersemiótica é abordada, neste artigo, através das relações de intertextualidade transmedial que se estabelecem entre Outra volta do parafuso, de Henry James, e as ilustrações de Charles Demuth sobre o conto. Ao averiguar se essas ilustrações seriam simples traduções intersemióticas ou transposições intersemióticas autênticas (Hoek), o artigo simultaneamente discute as controvérsias cruciais do conto: a realidade ou irrealidade das aparições, a coexistência ou não do bem e do mal nas crianças e a credibilidade da narradora.

PALAVRAS-CHAVE: transposição intersemiótica, literatura, pintura, Henry James, Charles Demuth.

ABSTRACT: This article discusses the issue of intersemiotic transposition by way of the transmedial intertextual relations between Henry James's The Turn of the Screw and Charles Demuth's illustrations for the tale. By investigating whether these illustrations are merely intersemiotic translations or authentic intersemiotic transpositions (Hoek), this article will simultaneously be reevaluating the crucial controversies concerning the tale: the reality or unreality of the apparitions, the coexistence or not of good and evil in the children, and the narrator's credibility.

KEYWORDS: intersemiotic transposition, literature, painting, Henry James, Charles Demuth.

\footnotetext{
* Centro Universitário Campos de Andrade, Curitiba, PR. Professora titular de Literaturas de Língua Inglesa (aposentada) da UFPR. Pós-doutorado em Literatura Norte-Americana e Inglesa.sigridrenaux@terra.com.br
} 

A reflexão sobre a transposição de obras de arte para outras mídias e, consequentemente, a discussão teórica a respeito de relações intersemióticas ou intermidiáticas deram origem a uma série de novos trabalhos críticos sobre literatura e artes visuais, e, especificamente, sobre o entrelaçamento e a interpenetração do texto escrito e da imagem. Dentro desta perspectiva, este artigo visa trazer à tona e rediscutir - através da transposição intersemiótica que o pintor e ilustrador norte-americano Charles Demuth realiza, em cinco aquarelas, sobre o conto The Turn of the Screw ${ }^{1}$ (1898) de Henry James - questões essas já amplamente debatidas pelos críticos, mas que continuam fascinando os leitores desta obra bem como os apreciadores/ espectadores das transposições intermidiáticas da mesma em ilustrações, filmes, peças teatrais, televisivas e ópera de câmera: ${ }^{2}$ a realidade/irrealidade das aparições, a coexistência ou não do bem e do mal nas crianças e a credibilidade da narradora (ver RENAUX, 1992).

\footnotetext{
${ }^{1}$ Outra volta do parafuso. Rio de Janeiro: Civilização Brasileira, 1969. 2. ed. Tradução de Brenno Silveira. Todas as referências a esta obra serão apresentadas como OVP seguidas do número da página.

${ }^{2}$ Ver, entre outros, a ilustração de John La Farge (retratando Miles e a preceptora) e as de Eric Pape por ocasião da publicação do conto em Collier's Weekly, An Illustrated Journal, de janeiro a abril de 1898; a peça teatral de William Archibald The Innocents (1961); o filme de Jack Clayton The Innocents (1961) e a ópera de câmera de Benjamin Britten The Turn of the Screw (1964).
} 
Levando-se em consideração que Charles Demuth (1883-1935) absorveu, durante suas diversas estadias na Europa, principalmente em Paris, a partir de 1907, os diversos movimentos estéticos dos inícios do século XX, interessando-se particularmente pela arte de vanguarda como o Cubismo e que, posteriormente, tornou-se um dos expoentes principais do Precisionismo - o Cubismo norte-americano na década de 1920 -, tornase evidente que suas ilustrações de The Turn of the Screw, como também de outros contos e romances, ${ }^{3}$ não podem ser consideradas simples traduções intersemióticas. Além disso, levando-se em consideração que "toda estimativa estética representa o encontro de duas sensibilidades, a sensibilidade do autor da obra de arte e a do intérprete", pois a interpretação é "o resultado da filtragem da expressão de outrem pela nossa própria personalidade" (PRAZ, 1982: 33), fica evidente que essas ilustrações seriam, simultaneamente, transposições de "estados de espírito" (1982: 94).

Diversos críticos já ressaltaram a qualidade artística dessas ilustrações, como James T. Soby, Andrew C. Ritchie, Robert Lee Wolff e William Murrell, entre outros. Ao apresentar a obra de Demuth, em New Art in America, Soby declara que, apesar de Demuth ser conhecido pelos amigos como esteta, dândi e gourmet, apaixonado por viagens e lugares públicos como cabarés e teatros, sua arte era essencialmente pessoal, mesmo secreta: originava-se

from an aristocratic withdrawal of spirit which left him free to comment sharply, and with remarkable originality and skill, on subjects from life and literature that interested him deeply. He was most at ease with watercolor, a medium whose requirements of delicacy and precision suited his slender, firm hands (SOBY, 1957: 50).

Também em Contemporary American Painters Soby comenta como as primeiras aquarelas de Demuth já poderiam ser classificadas em duas categorias: aquelas em que o "detalhe ilustrativo" era importante e, entre elas,

\footnotetext{
${ }^{3}$ Demuth também ilustrou, entre outros, os contos "The Beast in the Jungle" de James, "The Mask of the Red Death" de Poe, as peças teatrais Die Büchse der Pandora e Erdgeist de Wedekind, os romances La fille aux yeux d'or de Balzac, L'Assommoir e Nana de Zola, além de diversos "poster portraits" - pinturas abstratas de diversos amigos - como "The Figure Five in Gold", inspirada pelo poema "The Great Figure" (1920) de William Carlos Williams e um tributo do pintor ao poeta. "The Figure Five in Gold" encontra-se analisada por Claus Clüver em "Da transposição intersemiótica" (2006).
} 
suas interpretações de autores preferidos; e aquelas que comparativamente eram organizadas formalmente. Constata também que Demuth parece ter usado ambos os estilos alternadamente em vez de ter progredido de um para o outro. Seu "estilo ilustrativo" revela que, em questão de decoração e inspiração literária, Demuth preferia o século XIX, com sua mobília pesada e bric-a-brac exótico, predileção esta que fica evidente nas ilustrações de interiores com figuras. Até as datas dos livros que Demuth ilustrou tornam clara sua devoção pelo século anterior ao seu - obras de Balzac, Zola, Poe, James e Wedekind (SOBY, 1948: 12). Soby ainda complementa que

time and again in viewing Demuth's figure pieces a fin de siècle reminiscence suggests itself - an attenuated shoe and foot out of Beardsley, a woman's profile drawn with Lautrec's jagged, incisive contours. Yet Demuth was able to assimilate and make his own even these vigorous sources, partly because of his own decided originality and partly because of the very cultivation of his taste. (1948: 12)

Todas essas características apontadas por Soby serão retomadas em nossa leitura das aquarelas de Demuth, pois servirão como pontos de apoio para avaliarmos melhor a transposição intersemiótica que o ilustrador fez de cenas de The Turn of the Screw, bem como o fato de que Soby já havia percebido que Demuth conseguira não só assimilar mas "tornar próprias" as influências recebidas de Aubrey Beardsley e Toulouse-Lautrec, a quem Demuth "idolatrava" (SOBY, 1948: 12).

Ritchie, em Charles Demuth, confirma igualmente como as aquarelas de Demuth captavam o espírito de James de maneira admirável:

And as for the James illustrations, they have rightly been called Demuth's masterpieces. Rarely, if ever, has the mood and atmosphere of two stories [The Turn of the Screw e The Beast in the Jungle] been more perfectly translated into visual terms. Demuth's affinity for James must have been extremely close to arrive at such sympathetic understanding. (1950: 12)

E, ao ampliar sua apreciação crítica sobre as ilustrações de Demuth, inserindo-as na época em que foram feitas, Ritchie ainda acrescenta que

the stories and plays that appealed to Demuth for illustration are very significant with reference both to himself and his time. Almost without exception, they deal with sex as a symbol of social degeneracy. [...] James's horror stories are extremely subtle expositions of sexual perversion or dislocation (1950: 12), 
atribuindo esta preocupação com o mórbido e o perverso a um profundo desequilíbrio e inquietação na própria índole de Demuth, que era manco e de compleição débil. Entretanto, conclui Ritchie, essas ilustrações refletem muito mais do que uma morbidez pessoal e deveriam ser vistas como "distillations of that period of aesthetic bohemianism that flowered during the first two decades of this century and whose roots were in Paris, London and Berlin. Here is their supreme interest" (1950: 13).

Esta orientação da apreciação crítica de Ritchie, em relação à preocupação de Demuth com o mórbido e perverso em James, já estava presente em Wolff ao este afirmar que as quatro ilustrações de cenas do conto que Demuth escolheu reproduzir ("At a House in Harley Street" não está incluída), com suas formas e expressões torturadas, são uma prova positiva de que ele considerava a preceptora, que vê os fantasmas e conta a história, "as a neurotic, suffering from sex repression" (1966: 125-6). E, como ele confirma em nota de rodapé no mesmo artigo, após enumerar os títulos das ilustrações, "Demuth has deliberately chosen four scenes with ambiguous meanings and hidden sexual significance" (1966: 126).

Outros críticos confirmam os pontos de vista de Soby, Ritchie e Wolff, ao enfatizarem, em suas apreciações, como a obra de Demuth incluía "ilustrações sinistras e sexualmente mórbidas" de livros como Nana e The Turn of the Screw (CHILVERS, 1999), ou como suas ilustrações literárias, especialmente de cenas de The Turn of the Screw, mostram, além da genialidade de sua arte, uma faceta da sensibilidade de Demuth não aparente nos quadros com flores ou com cenas de festa - seu gosto pela violência emocional (KRAMER, 2004). Ou ainda, como seu "estilo linear e sensível" se ajustava admiravelmente para ilustrar peças teatrais e romances, ilustrações essas que, feitas sem a intenção de serem publicadas, refletiam o gosto de Demuth pelo psicologicamente deformado e retratavam conflito sexual e decadência social (ENCYCLOPEDIA..., 2005-6).

As avaliações críticas das aquarelas de Demuth tornam-se entretanto ainda mais complexas na apreciação de William Murrell, ao comentar que suas ilustrações para The Turn of the Screw e The Beast in the Jungle

are instances of extraordinary imaginative sympathy and suppleness of execution. Demuth implies that the figures in James's great ghost story are themselves ghosts - wraiths evoked by the luminous mind of their author. And he presents these unreal people with a vividness that comes as a shock, and a sensitiveness that is comparable only to the words of James himself. The real tragedies of minute embarrassments, and of the too long unspoken word - 
these are rendered by Demuth in drawing that is deceptively loose, deliberately nervous, utterly unconventional. And the watercolor serves to heighten the grimness, the pathos, or the blankness of the chosen moment. (1931:9-10)

Partindo dessas diversas avaliações da obra de Demuth e tendo como aporte teórico, entre outros, os ensaios de Leo Hoek "A tradução intersemiótica: por uma classificação pragmática”, e de Claus Clüver "Da transposição intersemiótica”, nos quais são investigados os tipos de relações entre o texto e a imagem e o conceito de transposição intersemiótica, nossa leitura das ilustrações de Demuth pretende averiguar até que ponto elas seriam apenas fiéis ao seu "texto-fonte verbal" (CLÜVER, 2006: 140) o conto de James - e, portanto, como discurso secundário próximo ao primário, "simples traduções intersemióticas"; ou se, pelo contrário, afastando-se do texto primário, tornam-se "transposições intersemióticas autônomas" (HOEK, 2006: 178), sempre em relação às grandes questões que o conto suscita, mencionadas acima. A leitura simultânea do texto de James torna-se portanto indispensável para apreciar e avaliar "o conteúdo representacional" (CLÜVER, 2006: 143) e a interpretação pictural feita por Demuth.

\section{AS ILUSTRAÇÕES}

As cinco ilustrações de Demuth foram feitas em 1918, portanto vinte anos após a publicação de The Turn of the Screw. O fato de Demuth haver feito as ilustrações sem a intenção de publicá-las, como mencionado, sugere que elas foram aparentemente executadas para seu próprio deleite, a fim de expressar sua fascinação pelo conto de James. As cenas escolhidas por Demuth, baseadas em trechos específicos retratando momentos ambíguos e/ou culminantes da narrativa, confirmam o impacto e a forte impressão que as mesmas causaram nele e, como afirma Sweeney, o fato de Demuth estar "under 'the literary spell' of The Turn of the Screw" (1943: 523). ${ }^{4}$

\footnotetext{
${ }^{4}$ Sweeney inicia o artigo comentando que James estava ciente "of the dangers of distraction likely to follow from the presence of illustrations accompanying the text". Mesmo assim, ele aceitava a ilustração se ela aparecesse como "a separate and independent subject of publication", suficientemente afastada do texto de modo a não colocar uma obstrução entre o escritor e o leitor. Sweeney ainda comenta que as aquarelas de Demuth são hoje reconhecidas como "outstanding examples of American water-color painting. And their value as independent works of pictorial art, for all their literary inspiration is undoubtedly due to Demuth's scrupulous and constant allegiance as a painter to "his own other medium" - "his own other art". (1943: 522)
} 
Todas as ilustrações, por sua vez, revelam o estilo característico de Demuth, como constatado por Soby: "in nearly all his watercolors, Demuth appears to have overlaid color on an image more or less completely drawn in pencil" (1948: 13). Esta constatação é muito significativa em relação às ilustrações, pois, pelo fato de os inúmeros traços feitos a lápis serem perfeitamente visíveis sob o colorido da aquarela, e ainda ressaltados nas partes em que há pouca ou nenhuma cor, as citações introduzidas nas ilustrações parecem fazer parte dos traços a lápis das mesmas, integrando/imbricando perfeitamente o texto verbal com o visual. Assim, já antecipando algumas possíveis conclusões, as relações intersemióticas que se estabelecem entre texto e imagem, mesmo que primordialmente "transmediais", através da transposição, como será visto, não deixarão de ser, em grau menor, também um "discurso multimedial”, pela justaposição imagem-texto, um "discurso misto", através da combinação imagem-texto e até um "discurso sincrético", pela fusão imagem-texto (HOEK, 2006: 185). Pois, como argumenta Clüver, "a relação de uma ilustração com o seu textofonte verbal pode ser tão variada quanto a relação de um poema ekfrástico com a obra visual que ele evoca" (2006: 140).

\section{I - A PRECEPTORA NA MANSÃO DA RUA HARLEY}

A primeira ilustração, com o título "At a House in Harley Street" (Figura 1) seguido pela assinatura de Demuth e data, colocados no canto direito da mesma, refere-se a uma passagem específica do conto: o momento em que o tio e tutor das crianças, agradecendo à preceptora por ter aceito o trabalho de cuidar das mesmas, retém por um momento sua mão. Como a cena é descrita em James na introdução à narrativa - através do relato oral e escrito que a preceptora havia feito a um senhor e lido vinte anos mais tarde por ele a um grupo de pessoas reunidas em volta de uma lareira, contando histórias de "aparições" -, o tio que anunciara o emprego,

tal como se apresentou aos olhos da candidata, numa vasta e imponente mansão de Harley Street, lhe pareceu um perfeito cavalheiro, um homem solteiro ainda no vigor dos anos, uma figura, enfim, como jamais surgiu, salvo em sonhos ou numa velha novela, diante de uma trêmula e ansiosa jovem recém-chegada de uma pequena localidade de Hampshire. [...] Era elegante, ousado, sedutor, cheio de entusiasmo, alegria e bondade. Como bem se pode imaginar ele a impressionou pela elegância de suas maneiras e pelo seu aspecto físico, mas o que nele mais a seduziu, inspirando-lhe a coragem que revelou mais tarde, 
foi a sua maneira de referir-se ao trabalho que ela iria executar, como se fosse uma espécie de favor que ela lhe faria. [...] Ela prometeu que assim o faria, e confessou-me que, quando ele, por um momento, reteve a sua mão, aliviado, encantado, agradecendo-lhe aquele sacrifício, ela já se sentira recompensada. (OVP: 9)

A ilustração resgata então este momento de gratidão, por parte do cavalheiro, para com a futura preceptora de seus sobrinhos, mostrando-o de pé, segurando as mãos desta "trêmula e ansiosa jovem", sentada, de costas para o espectador. Como já mencionado, a preferência de Demuth pelo século XIX em questão de decoração, com sua mobília pesada e seu bric-a-brac exótico, fica evidente na retratação do interior desta "imponente mansão de Harley Street": grandes poltronas vermelho-escuras e as cortinas, da mesma cor, parcialmente vedando uma janela; as cadeiras de braço em madeira trabalhada, a lareira iluminada sobre a qual se encontram troféus de caça, e, na parede ao fundo, uma máscara exótica, fantasmagórica. Emoldurando as figuras centrais, a ilustração deste ambiente confirma, em sua imponência, a elegância das maneiras e a sedução que o tio das crianças exerceu sobre a preceptora, pois é a partir deste primeiro e único encontro que irá se desencadear toda a paixão da preceptora por sua figura "como jamais surgiu, salvo em sonhos ou numa velha novela diante de uma trêmula e ansiosa jovem recém-chegada de uma pequena localidade de Hampshire", paixão esta que irá ser reinterpretada, indiretamente, na próxima ilustração.

Todos estes detalhes decorativos, mesmo que não se encontrem no texto de James citado acima, serão entretanto recuperados no decorrer da narrativa pela preceptora/narradora, ao descrever, em diversas ocasiões, detalhes da mansão de Bly, na qual iria morar como preceptora das crianças. Mais ainda, esses detalhes simultaneamente prenunciam /antecipam elementos que serão utilizados por James para "emoldurar" as aparições de Peter Quint e Miss Jessel - os antigos preceptores das crianças: se a lareira aparece na introdução ao conto como o local em volta do qual um grupo de pessoas contava histórias "estranhas", ela também prefigura, por analogia, os estranhos acontecimentos que a preceptora irá narrar; a janela será palco da segunda e da última aparição de Quint e a enorme máscara exótica, por sua vez, antecipando o horror que a proximidade das visões de Quint iria despertar na preceptora, como será visto na última ilustração; o espaldar torneado da cadeira na qual está sentada a preceptora irá, por sua vez, também reaparecer na última ilustração. 
A representação da figura do tio, em sua posição vertical em frente à preceptora sentada, além de torná-lo o ponto central da ilustração, enfatiza sua superioridade social em relação a ela, enquanto seu terno escuro faz nossa atenção se prender ao rosto e às mãos, segurando as mãos (invisíveis) da preceptora. $\mathrm{O}$ detalhe das mãos, único contato físico entre ambos, será retomado em todas as outras ilustrações, também com relação às demais personagens, com outras implicações.

Da preceptora vemos apenas os ombros, recostados ao espaldar de uma cadeira, com a parte visível de seu perfil fitando o tio das crianças, que está a olhar para ela. A ampla gola de seu casaco escuro, que acompanha as linhas do espaldar da cadeira, bem como o chapéu da mesma cor que complementa o traje, ressaltam não só a alvura de seu rosto como também a cor dourada de seus cabelos cacheados, presos e parcialmente escondidos pelo chapéu.

Se o chapéu, por estar relacionado com a cabeça, já é simbólico do pensamento, e, portanto, mudar de chapéu equivale a mudar de ideias (VRIES, 1974: 240) - detalhe que será retomado nas outras ilustrações de Demuth -, o fato de o formato do chapéu, com a copa enformada como um barrete, ter na parte frontal dois enfeites em formato de asas verticais - com suas várias conotações simbólicas de aspiração, virtude, autoridade, poder, proteção, a mente, a alma, fantasia, amor, vitória, cura, mas também desgraça (VRIES, 1974: 503-4), conotações essas que uma leitura atenta da personagem irá confirmar -, ele nos remete, por analogia, às duas correntes interpretativas mais importantes que a figura da preceptora já despertou em leitores e críticos: a chamada crítica freudiana ou antiaparicionista, que caracteriza a narradora como sendo um caso neurótico de repressão sexual e as aparições apenas como alucinações por parte da mesma e, por outro lado, a crítica aparicionista, que considera a narradora uma vítima de visitações sobrenaturais, razão pela qual ela se sente na obrigação de, com sua autoridade, proteger e "salvar" as crianças. Estas facetas também irão ser retomadas por Demuth nas outras ilustrações, demonstrando assim a sensibilidade interpretativa do ilustrador em relação às grandes questões que o conto levanta.

A toda esta sensibilidade e percepção de sua arte ilustrativa, que transparece através da aquarela - este processo de pintura sobre papel em que são utilizadas tintas diluídas em água, e que se caracteriza pelo uso de cores transparentes sobre um fundo branco ou claro -, e que é considerada o ponto forte de Demuth, acrescenta-se ainda seu estilo característico: o 
"detalhe ilustrativo" na decoração do ambiente, a distorção maneirista dos contornos dos objetos e figuras criando efeitos bizarros - como a máscara fantasmagórica na parede ao fundo -, a aplicação da aquarela ressaltando o contraste entre as superfícies claras e as escuras - principalmente os rostos e as mãos das figuras em contraste com seus trajes, além do contraste no mobiliário -, todos eles evidenciando a tentativa/intenção de Demuth em não apenas retratar uma cena do conto mas transpô-la semioticamente, expressando-a e interpretando-a de modo a colocá-la também como ponto de partida para as outras ilustrações.

\section{II - A PRECEPTORA VÊ QUINT}

Em contraste com a primeira ilustração, ancorada numa "realidade objetiva" - o encontro da preceptora com o tio das crianças -, a segunda ilustração (Figura 2), com a citação "I can see - the way his hand - passed from one crenellation to the next" escrita no canto direito da aquarela, retrata os momentos finais da primeira visão que a preceptora tem de Quint. Esta visão ocorre precisamente num entardecer, quando ela, aproveitando a hora de descanso, passeia sozinha pelos jardins de Bly a fim de melhor absorver a "beleza e a dignidade do local". Como ela caracteriza mais tarde a atmosfera destes primeiros encontros, "havia no ar condições exatas de som e de quietude, de impressões indescritíveis da espécie daquelas que anunciam tais momentos de receptividade, como ocorrera quando, estando eu no jardim, naquela tarde de junho, deparei com Quint no alto da torre" (OVP: 87).

É neste estado propiciatório de espírito, quando a preceptora, em suas caminhadas, imaginando "que seria tão encantador como um conto encantador se eu me encontrasse subitamente com alguém. Alguém aparecia, de repente, na volta do caminho e ficaria parado a fitar-me, sorrindo, com ar de aprovação" - numa clara alusão ao tio das crianças -, que se concretiza a aparição de Quint, ao ela se deter subitamente e deparar com a casa à sua frente, acrescentando: "O que me pregou no chão [...] foi a sensação de que a minha fantasia, num abrir e fechar de olhos, se tornara real. Lá estava ele!... mas muito alto, além do relvado, no próprio topo da torre" (OVP: 26-27).

Entretanto, ao perceber seu engano, que "o homem que surgia ante os meus olhos não era a pessoa que eu, precipitadamente, supusera", percebe também que 
o próprio lugar, da maneira mais estranha do mundo se transformara, no mesmo instante, devido à sua aparição, numa profunda solidão. [...] era como se o resto do cenário houvesse sido ferido de morte. [...] $\mathrm{O}$ ouro permanecia ainda no céu, a transparência na atmosfera, e o homem que me fitava do alto das ameias podia ser visto tão claramente como um retrato numa moldura. (OVP: 27)

Ela continua sua rememoração do encontro:

através da distância, defrontamo-nos durante um espaço de tempo bastante longo para que eu me perguntasse, [...] quem poderia ser, e para que sentisse [...] um assombro cada vez maior. [...] Ele se encontrava num dos ângulos mais afastados da casa, muito erecto, pormenor que me chamou a atenção, e tinha as mãos apoiadas no parapeito. Foi assim que eu o vi [...] depois, [...] como para aumentar o efeito da cena, mudou lentamente de lugar, passando, sem deixar de olhar-me fixamente durante todo tempo, para o lado oposto da plataforma. [...] não tirou jamais os olhos de mim - e, ainda agora, neste momento em que escrevo, posso ver o movimento de sua mão, pousando, sucessivamente, nas ameias. (OVP: 28)

É portanto a partir deste contexto que Demuth criou sua segunda ilustração. Se na primeira retratou o interior da imponente mansão da Harley Street, com suas cores quentes, móveis pesados e bric-a-brac, ele retrata agora, contrastivamente, o cenário e a atmosfera dos jardins de Bly, no exato momento em que a preceptora, sobressaltada e atônita, tendo perdido a noção de tempo, observa o homem que a fitava "do alto das ameias" (OVP: 28). Esta atmosfera crepuscular - já caracterizada por James como anunciadora de momentos de receptividade e que, portanto, "permite e propicia uma aparição entre dois mundos” (RENAUX, 1992: 167) - e este cenário, transformado repentinamente numa profunda solidão, como se houvesse sido ferido de morte, são transpostos por Demuth através do uso de um fundo expressionista: nuvens, pássaros, colinas e arbustos, em tons de cinza claro e escuro, desenham-se de modo a sugerir uma paisagem fantasmagórica, retratando não a "realidade objetiva", mas as emoções e respostas subjetivas que os elementos da natureza descritos por James suscitaram no artista. A formação de um tornado se aproximando, insinuado pelo traço sinuoso vertical escuro entre as nuvens, aumenta a signicidade ameaçadora do cenário. 
O mesmo procedimento expressionista é usado em relação à preceptora: sua figura, colocada no primeiro plano sobre o fundo fantasmagórico descrito acima, alonga-se, contorcida, por toda a altura da mesma. Por estar um pouco à esquerda do centro da ilustração, sua posição está relacionada simbolicamente com o feminino, o inconsciente, o sinistro e o mágico, como também com espíritos malignos (VRIES, 1974: 386), o que condiz com a ambiguidade da cena em James. Em contraste com a ilustração anterior, a visualização de sua figura inteira, de frente, em primeiro plano, torna-a o centro de atenção, enquanto os tons bem escuros de seu traje aumentam o impacto de sua materialidade e visibilidade em relação ao fundo esmaecido. Além disso, sua postura ereta, mesmo que contorcida, remete-nos à figura do tio das crianças, em pé, na primeira ilustração, o que confirma ela estar se lembrando dele ao passear pelos jardins, como também nos remete à postura de Quint, no alto da torre - "muito erecto, pormenor que me chamou a atenção" -, deste modo facilitando a identificação errônea que a preceptora fez, num primeiro instante, de tomar a figura do homem no alto da torre pela do homem por quem estava apaixonada.

Por esta razão, os outros detalhes de sua figura dão à sua aparência aquela deformação típica do expressionismo - os pés afastados enfatizando o formato triangular da saia; os ombros largos, acentuados pela jaqueta, e os braços alongados se juntando nas mãos sobrepostas sobre a saia, formando um outro triângulo - deformação ainda acentuada pelo predomínio do preto no traje e pela expressão do olhar, sugerindo estar em êxtase amoroso: ela e a figura no alto da torre fitavam-se "de maneira direta" e ele, enquanto mudava lentamente de lugar, não deixava de olhá-la "fixamente" (OVP: 28-29). Simultaneamente, os detalhes apontam para a interpretação que Demuth imprime à cena, a partir da citação "posso ver o movimento de sua mão, pousando, sucessivamente, nas ameias" (OVP: 29): através dos gestos de Quint, com implicações eróticas, acentua a repressão sexual da preceptora. Como Wolff comenta a respeito, "the governess's expression of rapture in this picture is masterly" (1966: 126). Estes "detalhes ilustrativos" têm sua signicidade ainda ressaltada pelo fato de os pés, como símbolo de poder, e em contato direto com a terra, também possuírem poder mágico, além de serem um símbolo fálico (VRIES, 1974: 197), o que é ainda acentuado pelo fato de o triângulo formado pela saia, com o vértice para cima, simbolizar o masculino (1974: 475), aprofundando uma vez mais a ambiguidade da visão da preceptora. 
Em contraste com os pés, a cabeça, novamente com a parte superior coberta por um barrete e inclinada também para a esquerda - reforçando assim as conotações simbólicas mencionadas acima -, aparece apenas parcialmente, pois a borda da ilustração corta-lhe a parte direita da testa. Deste modo, destaca-se, por um lado, a cabeça - simbólica de pensamento (VRIES, 1974: 243) - em transe entre as nuvens, recuperando a lembrança do sonho, da fantasia da preceptora, em ver o tio das crianças no alto da torre; por outro, a expressão do olhar, corroborada pelo simbolismo dos olhos como expressão da alma e como abertura tanto para o mundo exterior como para a pessoa interior (1974: 170), revelando seu estado de êxtase.

As mãos sobrepostas, por sua vez, remetem não apenas à citação de James na ilustração, numa transposição da imagem (invisível) das mãos da figura no alto das ameias para a imagem visível das mãos da preceptora em pé, no primeiro plano. Recuperam também, por analogia, a imagem das mãos do tio das crianças segurando as suas, por um instante. Mas, além dessas relações, as mãos da preceptora, como "manifestação corporal do estado interior do ser humano" (RENAUX, 1992: 173) e como expressão de força e atividade, exercem uma outra função: pelo fato de estarem colocadas, sobrepostas, no vértice inferior do triângulo formado pela parte superior do corpo da preceptora, elas simbolizam o feminino e, portanto, reforçam mais uma vez a sugestão de repressão sexual da preceptora.

Se os detalhes da figura da preceptora ao se defrontar com Quint parecem não deixar dúvidas quanto a seu estado de êxtase erótico, à sua repressão sexual, como os críticos posteriores às ilustrações o fizeram, por outro lado Demuth também ressalta a ambiguidade da atmosfera crepuscular, tão propícia ao surgimento de "aparições", revelando assim sua profunda sensibilidade a todas essas alternativas, ao exacerbar esses aspectos que existem em potencial no texto de James.

\section{III - FLORA E A PRECEPTORA}

Novamente em contraste com a ilustração anterior, com sua austeridade quase monocromática ressaltando o estado de transe em que se encontra a preceptora como também o cenário fantasmagórico, "ferido de morte", a terceira aquarela (Figura 3) contém, além da citação do conto "She had picked up a small flat piece of wood" no canto direito e da assinatura de Demuth no canto esquerdo, ainda o título "Flora", colocado entre o lado esquerdo e o centro da ilustração, sinalizando portanto que a menina seria o ponto focal da mesma. 
A ilustração de Demuth irá recuperar praticamente todos os detalhes da cena em que James retrata a preceptora e Flora, à margem do lago de Bly, durante um passeio. Como a preceptora narra,

Não me recordo qual era meu papel nessa ocasião; lembro-me apenas que [...] Flora brincava com muita seriedade e empenho. [...] Súbito [...] percebi que, da margem oposta [...], um espectador muito interessado nos observava. [...] eu estava sentada com um trabalho nas mãos [...] num velho banco de pedra existente diante do lago, e, naquela posição, mesmo sem erguer os olhos, comecei a sentir a presença, à distância, duma terceira pessoa. As velhas árvores, os arbustos espessos, formavam uma grande e agradável sombra, mas estava tudo mergulhado no tranquilo e cálido resplendor da hora. [...] entrementes, [...] volvi os olhos para a pequena Flora, que, naquele instante, estava a uns dez passos de distância. Durante um instante, meu coração parou de bater, ao perguntar-me, cheia de espanto e terror, se ela também o veria [...] Fiquei à espera, mas nada aconteceu; depois [...] tive a sensação de que, havia já um minuto, ela havia cessado de fazer qualquer ruído, bem como a de que dentro desse minuto, sem deixar de brincar, havia voltado as costas para o lago. Essa era a sua atitude quando, por fim, a olhei, com a firme convicção de que ainda estávamos, ambas, submetidas a uma observação direta e pessoal. Flora apanhara do chão um pedaço de madeira chata, que tinha um pequeno orifício, o qual, evidentemente, lhe sugerira a idéia de introduzir no mesmo um outro fragmento, que poderia servir de mastro e fazer daquilo uma espécie de barco. Quando a observei, ela procurava, muito concentrada, ajustar em seu lugar o pedaço de madeira. Fiquei tão apreensiva diante do que ela estava fazendo que, após alguns segundos, senti que estava preparada para o que viesse depois. Então, ergui de novo os olhos... e enfrentei o que devia enfrentar. (OVP: 48-50)

A ambiguidade da cena - deixando em suspenso se apenas a preceptora vê essa "terceira pessoa", ou seja, a aparição de Miss Jessel na outra margem do lago, como lhe será revelado mais tarde por Mrs. Grose, ou se também Flora a vê ou pressente - é novamente mantida por Demuth: uma preceptora atônita olha, aterrorizada, para esta "espectadora", enquanto Flora parece manter os olhos no brinquedo.

Novamente em contraste com as ilustrações anteriores, o cenário desta vez é uma tarde de verão nos jardins de Bly, cena em que a luminosidade e o calor do dia são contrastados com a sombra das árvores, onde ambas se abrigam. A complementaridade dos conceitos de luz/sombra, concretizada nesta cena banhada de luz mas com pontos sombrios, condiz com a atmosfera que James deseja criar (RENAUX, 1992: 197) e agora 
transposta expressionisticamente em Demuth: do lado esquerdo, troncos antropomórficos e contorcidos emoldurando a figura da preceptora, sentada num banco. Seus braços, abertos e apoiados sobre o banco de pedra, isomórficos, como também seu corpo, com os troncos, sugerem uma identificação entre a imobilidade das árvores e a da preceptora, ou seja, sua incapacidade de reagir, ao deparar com a aparição. Seu traje é novamente quase negro, com apenas uma gola branca quebrando a severidade da cor, enquanto seu barrete, também negro, ressalta seu perfil, expressando seu abalo interior, seu "espanto e terror". Pálida, boquiaberta e com olhos arregalados fitando algo do outro lado do lago, ela própria é uma figura quase tão fantasmagórica e assustadora como a aparição de Miss Jessel, descrita posteriormente por ela a Mrs. Grose: "uma figura em que transpareciam, inequivocamente, o horror e o mal; uma mulher de prêto, pálida e terrível... Com um ar também terrível... e que rosto!... do outro lado do lago" (OVP: 52). Deste modo, ela está descrevendo a si própria, na transposição de Demuth, que assim já antecipa, mais uma vez, novas perspectivas de interpretação que sugerem uma identificação latente entre Miss Jessel e a preceptora.

Em contraste com as tonalidades escuras das árvores e do traje escuro e pesado da preceptora, sentada, com a cabeça voltada para o lago, a figura translúcida de Flora está em primeiro plano e no centro da luminosidade do meio-dia: em pé, de costas para o lago, a cor rosa do vestido diáfano retomada na cor de suas pálpebras e faces, bem como na das flores à sua volta. Seus cabelos louros, encaracolados, estão reproduzidos na grande auréola luminosa à sua volta, irradiando cores, borboletas, flores, folhas e pássaros. Tudo está apenas esboçado: o contorno e a cor azul do lago, com vitórias régias, as borboletas, os arbustos com folhas e flores delineados como pássaros, os pássaros, em formato de flores, sobrevoando os arbustos, e a configuração de um barco ancorado aos pés de Flora. Destaca-se, portanto, a figura diáfana da menina, circunscrita por uma auréola de luz, sugerindo que ela está num mundo só seu, rodeada de luminosidades.

Entretanto, seu rosto está desviado para a direita e, mesmo com os olhos abaixados e de costas para o lago, seu olhar de soslaio revela que não está olhando para o "pedaço de madeira chata" que ela apanhara do chão - como consta na citação - e que retém nas mãos, o colorido escuro da madeira destacando ainda mais seu formato fálico. Ela está olhando para algo além dos arbustos e do barco, onde vemos, a partir do barco e ainda parcialmente dentro deste halo luminoso que a cerca, traços, cores 
e sombras que se delineiam evocando uma figura ou "aparição" feminina: as manchas escuras e longas sugerindo cabelos, o tronco sinuoso e claro esboçando um corpo, traços a lápis lembrando membros. Estes detalhes, tornando ambígua a auréola luminosa e pura em volta de Flora, insinuam estar ela ciente da presença de Miss Jessel, de sua presença oculta, mas implícita na versão visual de Demuth, e que no texto verbal, naquele instante, é sugerida apenas pelo silêncio total de sua pessoa e pela atenção dedicada ao brinquedo.

O detalhe do barco ancorado, que Flora posteriormente irá utilizar para chegar à outra margem do lago - vislumbrado em microcosmo através do detalhe do barco de brinquedo que Flora tentava construir - e portanto uma antecipação do que virá a acontecer, revela uma vez mais como Demuth vai além da tradução pictural de uma determinada cena, ao colocá-la sempre em contato com os acontecimentos anteriores e posteriores.

Pelo contraste claridade-sombra desta ilustração, sendo o ponto mais escuro da aquarela não a figura de Miss Jessel - como no conto de James - mas a da própria narradora, como visto, enquanto a suavidade das cores e luzes que envolvem a figura de Flora demonstra a delicadeza com que Demuth retratou a menina, confirma-se que "o claro-escuro serve não apenas para comunicar a sensação física de volume, [mas] também para sugerir sentimentos dramáticos, como entre os barrocos, românticos e modernos expressionistas" (CAVALCANTI, 1966: 85), pois o contraste claro-escuro, como já mencionado em relação à paisagem, também dramatiza o contraste entre a figura da preceptora e a de Flora, além de sugerir a presença simultaneamente clara-escura de Miss Jessel.

\section{IV - A PRECEPTORA, A MRS. GROSE E AS CRIANÇAS}

Se à ilustração anterior podemos aplicar o comentário de Barbara Novak "Demuth adapted romantic expressionism, with references to Rodin and Toulouse Lautrec, into an art of suggestion, coding veils of watercolor with a quavering line" (1969:271), pela sinuosidade sensual das linhas e pelas cores translúcidas do mundo de Flora contrastando com a figura severa e sombria da preceptora, a presente ilustração (Figura 4) irá apresentar outros ângulos pictoricamente interpretativos. Ela se refere à tarde em que a preceptora $\mathrm{e}$ a governanta, Mrs. Grose, do terraço, observam as crianças que brincavam "da maneira mais dócil possível" a certa distância, mas ao alcance da voz, e tem como ponto de partida a seguinte citação (não colocada na ilustração) do texto-fonte: "They moved slowly, in unison, below us, over the lawn, 
the boy, as they went, reading aloud from a storybook and passing his arm round his sister to keep her quite in touch. Mrs. Grose watched them with positive placidity" (JAMES, 1975: 65). ${ }^{5}$

O ponto focal, para o qual convergem os olhares da preceptora, sentada do lado direito, e da governanta, em pé do lado esquerdo, são as crianças, no centro da ilustração: caminhando lentamente pelo gramado, de costas, Miles abraçando Flora e aparentemente lendo para ela um livro de histórias. Entretanto, este ponto focal está dominado, em termos de perspectiva como "técnica de representação tridimensional que possibilita a ilusão de espessura e profundidade das figuras, a partir da projeção das linhas paralelas do primeiro plano para um ponto de fuga, de maneira que haja uma diminuição das figuras que ocupam o segundo plano da obra" (ENCICLOPÉDIA..., 2002) - pelas figuras da preceptora e da governanta, em primeiro plano.

A preceptora, sentada numa cadeira de braços e parcialmente de costas, com seu perfil novamente ressaltado pelo chapéu escuro que cobre parcialmente seus cabelos, revela um olhar pensativo, absorto, mesmo aparentemente centrado nas crianças. Pela primeira vez, ela está com um traje rosa claro - cor ressaltada ainda pelos traços leves, apenas delineados, da cadeira -, deste modo identificando-se com Flora na cor rosa do vestido, com suas conotações simbólicas de feminilidade, alegria, juventude (VRIES, 1974: 367), sugerindo portanto que ela também, neste momento, gostaria de ter o romantismo da menina. Uma enorme gola branca, plissada, contribui para a leveza de sua figura. Entretanto, o chapéu, simbólico de pensamento, como visto, por ser escuro, condiz com seu olhar pensativo, e com a interpretação que ela dará ao passeio das crianças.

Mrs. Grose, por sua vez, cujo traje e cabelos escuros contrastam pictoricamente com os da preceptora, tem sua "forma octoplásmica", ${ }^{6}$ grande e pesada, acentuada ainda mais por estar em pé, com o corpo ligeiramente inclinado para trás, como que para observar melhor as crianças. Apesar da touca, gola, avental e punhos brancos do uniforme - revelando assim sua

\footnotetext{
5 "Caminhavam de um lado para outro, lentamente, pelo gramado. Miles, que havia passado o braço em tôrno da cintura da irmã, para que Flora permanecesse junto dêle, lia, em voz alta, um livro de histórias" (OVP: 76).

${ }^{6}$ Como explicita Novak, "In his moving illustrations for James's The Turn of the Screw, he [Demuth] confronts us with octoplasmic forms and diaphanous washes that recall the nineteenth-century American concern with spiritualism" (1969: 271).
} 
posição subalterna -, os tons escuros da roupa ressaltam sua materialidade e proximidade e assim, também, as forças telúricas e o nível da realidade. $\mathrm{O}$ fato de estar de costas, apenas com o perfil delineado, como a preceptora, reforça a perspectiva de seu olhar, protetor e vigilante, em direção das crianças, ao contrário do olhar pensativo da preceptora, que - talvez por estar sentada, numa posição espacialmente inferior a da governanta - não converge, em termos de perspectiva, para o ponto de fuga: as crianças, a uma certa distância.

Este entrecruzamento de duas diferentes perspectivas e olhares é ainda ressaltado pelas linhas cruzadas em diagonal das colinas ao fundo, formando uma série de planos triangulares, alguns ligeiramente ondulados, à frente das crianças. Estas formas triangulares são reproduzidas claramente em miniatura, mais uma vez, na gola e touca de Mrs. Grose e no chapéu da preceptora, sugerindo uma integração personagem/fundo, no sentido de que ambos cercam as crianças que estão ao centro da ilustração. Mais ainda, as posições inclinadas de Mrs. Grose à direita e da preceptora à esquerda, suas figuras como que entreabrindo-se para visualizarmos Miles e Flora, formam mais um triângulo, colocando as crianças, com suas figuras diminuídas por estarem no segundo plano, como que dentro de uma moldura triangular. Esta distância, por sua vez, salientada pela moldura, coloca as crianças dentro de um duplo mundo ficcional: o delas, lendo histórias, em relação às duas senhoras e - como ficção dentro da ficção - em relação ao nosso, como leitores/espectadores das ilustrações.

Figuras frágeis à distância, de costas para o mundo da realidade das duas senhoras, Miles e Flora, abraçados, parecem caminhar despreocupados, aparentemente se entreolhando, pela posição convergente de suas cabeças. $\mathrm{O}$ contato de seus cabelos louros aproxima ainda mais suas silhuetas, enquanto o braço estendido de Miles, de camisa escura, segurando um livro aberto, contorna os ombros de Flora, em seu vestido rosa e levemente inclinada contra o irmão. $\mathrm{O}$ fato de os detalhes da parte inferior da figura de Miles estarem inacabados, em termos de cor, contribui para a leveza de sua figura, leveza esta já ressaltada na figura rósea de Flora. O ponto mais importante, talvez, é Miles estar lendo em voz alta para Flora, como consta na citação: pois, ao ler, estão vivendo as aventuras descritas, adquirindo conhecimentos mágicos através dos contos de fadas, que são também uma fuga ao mundo dos sonhos, fazendo com que as crianças não estejam "presentes" mesmo sendo vistas pela preceptora e pela governanta. 
Entretanto, toda esta cena idílica das crianças será interpretada pela preceptora, posteriormente, como se ambos estivessem em conluio com as "aparições" dos ex-preceptores, pois, como a preceptora comenta a mesma, no dia seguinte, para Mrs. Grose, "mesmo quando fingem estar absortos em seus contos de fadas, se acham voltados para a visão dos mortos que lhes aparecem. Neste momento, Miles não está lendo um conto para a irmã [...] finge que lê, mas estão falando dêles... estão falando de coisas horrorosas!" (OVP: 81). Por esta razão, o olhar pensativo da preceptora sobre as crianças, na ilustração, não se harmoniza com a realidade visível das mesmas - Miles lendo histórias para Flora - ao imaginar que elas apenas fingem que estão "absortos em seus contos de fadas", mostrando assim mais uma vez como Demuth transpôs não apenas uma cena, mas as implicações passadas e futuras desta cena no texto-fonte.

\section{V - A PRECEPTORA E MILES}

A última ilustração de Demuth, com a citação "Did I steal?" (Figura 5) inscrita no canto direito, retrata o momento culminante do conto, próximo ao desfecho - o encontro final da preceptora com Miles, no qual ela o interroga e o pressiona incessantemente: primeiro para fazê-lo confessar a verdade acerca da carta que ela havia escrito ao tio e que ele havia pego e lido; em seguida, para fazê-lo confessar o que fazia no colégio; para então, num exorcismo final, diante da aparição de Quint à janela, fazê-lo confessar que está ciente da presença das aparições à sua frente, o que leva o menino a sucumbir angustiado à sua pressão inexorável e morrer. Como a parte do diálogo inicial revela, ao ela perguntar o que ele fazia no colégio -

- Você apanhava as cartas... ou outras coisas?

- Outras coisas?

Parecia pensar em algo muito distante, que só chegava a êle devido à pressão de sua ansiedade:

- Pergunta se eu roubava?

[...] não. Eu não roubava.

Meu rosto devia certamente revelar que eu acreditava em suas palavras; mas minhas mãos - movidas por puro carinho - o sacudiram, como se eu lhe perguntasse por que razão, se nada havia a ocultar, me havia êle condenado a meses de tortura.

- Que foi que você fêz, então? 
Olhou para o teto com vago sofrimento e respirou duas ou três vezes como se lhe fôsse difícil responder. Dir-se-ia que se achava no fundo do mar e erguesse os olhos para uma fraca e verdadeira claridade.

[...] Eu tinha a impressão de que flutuava não em direção à luz, mas de uma escuridão ainda mais completa e, decorrido um minuto, ocorreu-me, vindo do fundo do meu espantoso alarme, a idéia de que êle talvez fôsse inocente. [...] Paralisada, naquele instante, pelo próprio impacto da questão, soltei um pouco as rédeas, de modo que, com um profundo suspiro, êle me voltou de nôvo as costas - e eu permiti que olhasse para a janela vazia, sabendo que agora nada lá havia que devesse ser evitado. (OVP: 146-8)

- é deste contexto que surge a pergunta específica sobre a qual Demuth recriou a cena: "Did I steal?” (JAMES, 1975: 118).

A ilustração tem como fundo uma tapeçaria marrom escura, parcialmente coberta por linhas verticais retas e quadradas, sugerindo estruturas maciças e dominadoras, assentadas por sua vez sobre um tapete retangular. Os tons marrons dessas paredes, que variam do ocre ao avermelhado, ao quase negro, sugerem, pela forma e pelas cores, biombos num cenário de teatro. As cadeiras de braço visualizadas à direita - com seu intricado desenho no encosto reproduzindo a cadeira na qual a preceptora estava sentada, na primeira ilustração - contrastam com a rigidez das linhas ao fundo e destacam a claridade da janela - também presente na primeira ilustração -, deste modo não apenas acentuando o contraste claro-escuro da cena, mas aproximando o cenário inicial do final, em termos de conjunto.

Emolduradas por este cenário encontram-se as figuras da preceptora e de Miles: a preceptora, ajoelhada, envolvendo Miles com os braços, parece estar falando com ele, pois sua boca está entreaberta, enquanto sua expressão facial revela estar atenta, pelo olhar, para algo além de Miles. Seus cabelos louros, de uma tonalidade um pouco mais escura que a do menino, e uma gola branca amenizam um pouco a sobriedade da cor cinzenta de seu vestido.

Já a expressão facial de Miles e seu gesto de repulsa ao abraço da preceptora revelam sua ansiedade e temor, pois seu braço direito procura afastar a parte superior de seu corpo do corpo da preceptora, formando assim um vão entre as duas cabeças. Seu outro braço, estendido ao longo do corpo, parece estar imobilizado. Sua jaqueta e gravata escuras, contrastando com a gola branca de sua camisa e com seu rosto infantil, acentuam assim a expressão de aversão em seu olhar. 
Se estes detalhes ilustrativos são facilmente detectados, o mesmo não ocorre com a visão que a preceptora tem de Quint. Diferentemente do texto-fonte, no qual a aparição de Quint é vista à janela, como descrito pela preceptora - "outra vez, encostado à vidraça, como para fazer malograr a sua [de Miles] confissão e reter a sua resposta, estava o odioso autor de nosso infortúnio - o rosto lívido e maldito" (OVP: 149) -, na ilustração de Demuth a aparição parece estar impregnada e portanto visível no biombo entre as cabeças afastadas da preceptora e de Miles: em tonalidades semelhantes às do biombo e do próprio tapete, a sugestão de seus traços horrendos e borrados mal se distinguindo das cores do biombo. Por outro lado, como o olhar da preceptora parece estar dirigido à janela, por trás de Miles, fica novamente a dúvida se a imagem de Quint está apenas potencialmente projetada por Demuth no biombo, a fim de sugerir que ele permanece na mente de ambos, ou se apenas a preceptora o vê, à janela, como o texto de James acima sugere. Deste modo, é conservada na ilustração toda a ambiguidade da cena em James, ao não sabermos se a aparição de Quint é vista apenas pela preceptora, ou também por Miles. É esta ambiguidade que faz a preceptora, através da tentativa de exorcização da eventual culpa de Miles, levar o menino à morte.

Lembrando-nos que "tanto na tradução interlingual quanto na transposição intersemiótica o sentido atribuído ao texto original, seja ele poema ou pintura, é o resultado de uma interpretação" (CLÜVER, 2006: 117), percebemos como Demuth, a partir do conto de James, muito mais do que retratar detalhes contidos nas citações, recuperou elementos anteriores e posteriores às mesmas, atribuindo assim aos signos visuais um significado polivalente, potencialmente aberto, como a própria obra de James, reforçando assim o aspecto mais crucial do texto-fonte: a ambiguidade do texto verbal.

A leitura das ilustrações de Demuth revela portanto sem dúvida que, ao reinterpretar o texto primário, acrescentando às ilustrações não apenas sua profunda sensibilidade para com a problemática do texto jamesiano, através da sutil manipulação de linhas, formas e cores, mas deixando em aberto as questões debatidas pelos críticos - relativas à realidade/irrealidade das aparições, à conivência ou não das crianças com os ex-preceptores e à própria credibilidade da narradora -, Demuth aprofunda e amplia a potencialidade das mesmas, transformando suas leituras pictóricas não "apenas" em "transposições intersemióticas autônomas", mas também em 
"um equivalente de essência" (CLÜVER, 2006: 108) da narrativa jamesiana, ao evocar com sua penetrante visão interpretativa uma realidade/irrealidade além da expressa pelas suas marcas visuais.

\section{REFERÊNCIAS BIBLIOGRÁFICAS:}

CAVALCANTI, Carlos. Como entender a pintura moderna. 2. ed. Rio de Janeiro: Civilização Brasileira, 1966.

CHILVERS, Ian. Demuth, Charles. A Dictionary of Twentieth-Century Art. 1999. Encyclopedia.com. Disponível em: <http://www.encyclopedia. com>. Acesso em: 9 maio 2009.

CLÜVER, Claus. Da transposição intersemiótica. IN: ARBEX, Márcia (Org.). Poéticas do visível: ensaios sobre a escrita e a imagem. Belo Horizonte: Editora UFMG, 2006. p. 107-166.

ENCICLOPÉDIA e dicionário Koogan-Houaiss digital. Rio de Janeiro: Hyper Mídia Editora, 2002.

ENCYCLOPEDIA of World Biography. Farmington Hills, MI: Gale Cengage Learning, 2005-6.

HOEK, Leo H. A transposição intersemiótica: por uma classificação pragmática. IN: ARBEX, Márcia (Org.). Poéticas do visivel: ensaios sobre a escrita e a imagem. Belo Horizonte: Editora UFMG, 2006. p. 167-190.

JAMES, Henry. Outra volta do parafuso. Trad. Brenno Silveira. Rio de Janeiro: Civilização Brasileira, 1969.

JAMES, Henry. The Turn of the Screw and Other Stories. Harmondsworth: Penguin Books, 1975.

KRAMER, Hilton. On Charles Demuth: Intimate Paintings, But Images Expand. 2004. Disponível em: <http://www.observer.com/node 48807>. Acesso em: 9 maio 2009.

MURRELL, William. Charles Demuth. American Artists Series. New York: Whitney Museum of American Art, 1931. 
NOVAK, Barbara. American Painting of the Nineteenth Century. New York: Praeger Publishers, 1969.

PRAZ, Mario. Literatura e artes visuais. São Paulo: Cultrix, 1982.

RENAUX, Sigrid. A volta do parafuso: uma leitura semiótica do conto de Henry James. Curitiba: Editora da UFPR, 1992.

RITCHIE, Andrew C. Charles Demuth. New York: The Museum of Modern Art, 1950.

SOBY, James T. Charles Demuth. IN: BAUR, John T. H. (Ed.). New Art in America. Greenwich: New York Graphic Society, 1957.

SOBY, James T. Contemporary American Painters. Brattleboro: E. L. Hildreth \& Co.; The Museum of Modern Art, 1948.

SWEENEY, John L. The Demuth Pictures. The Kenyon Review, v. 5, p. 522-532, 1943.

VRIES, Ad de. Dictionary of Symbols and Imagery. Amsterdam: NorthHolland, 1974.

WOLFF, Robert Lee. The Genesis of The Turn of the Screw. In: KIMBROUGH, Robert (Ed.). A Norton Critical Reader of The Turn of the Screw. New York: W.W.Norton \& Co., 1966. 


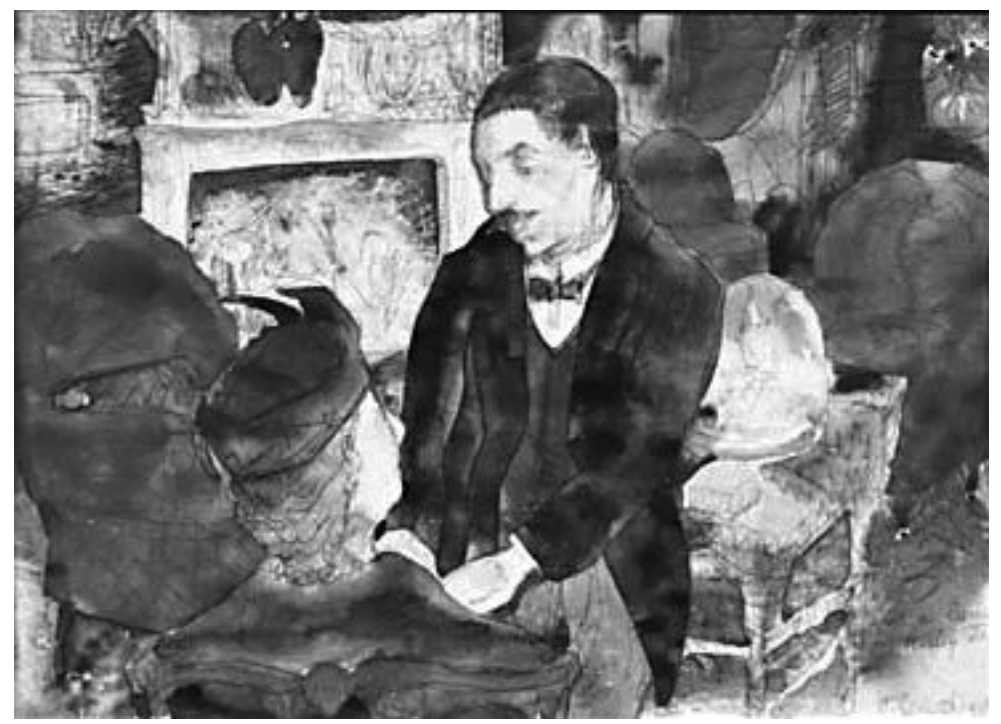

(Fig.1) "At a House in Harley Street". Watercolor, 8x 10 inches. Collection, The Museum of Modern Art, New York.

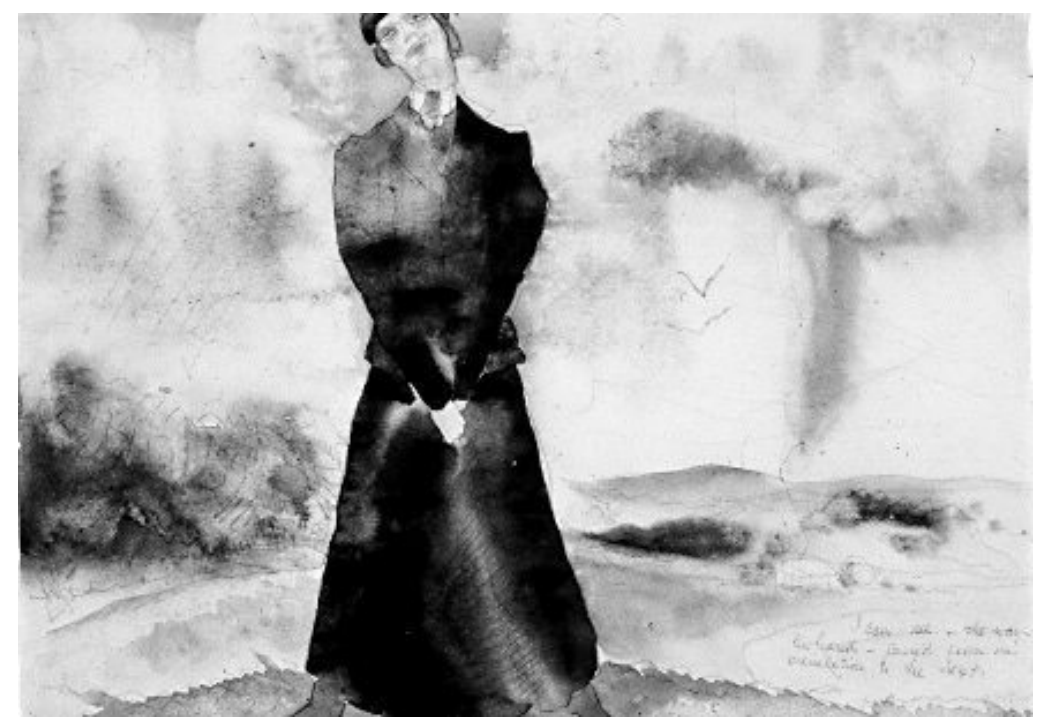

(Fig. 2) "I can see - the way his hand - passed from one of the crenelations to the next". Philadelphia Museum of Art. 


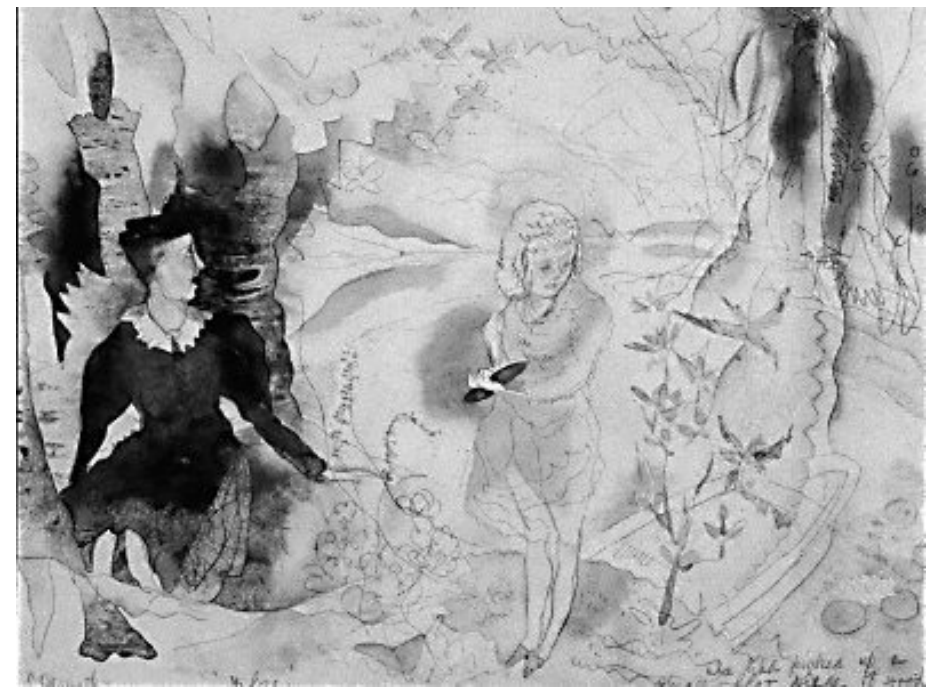

(Fig. 3) "She had picked up a small flat piece of wood". Philadelphia Museum of Art.

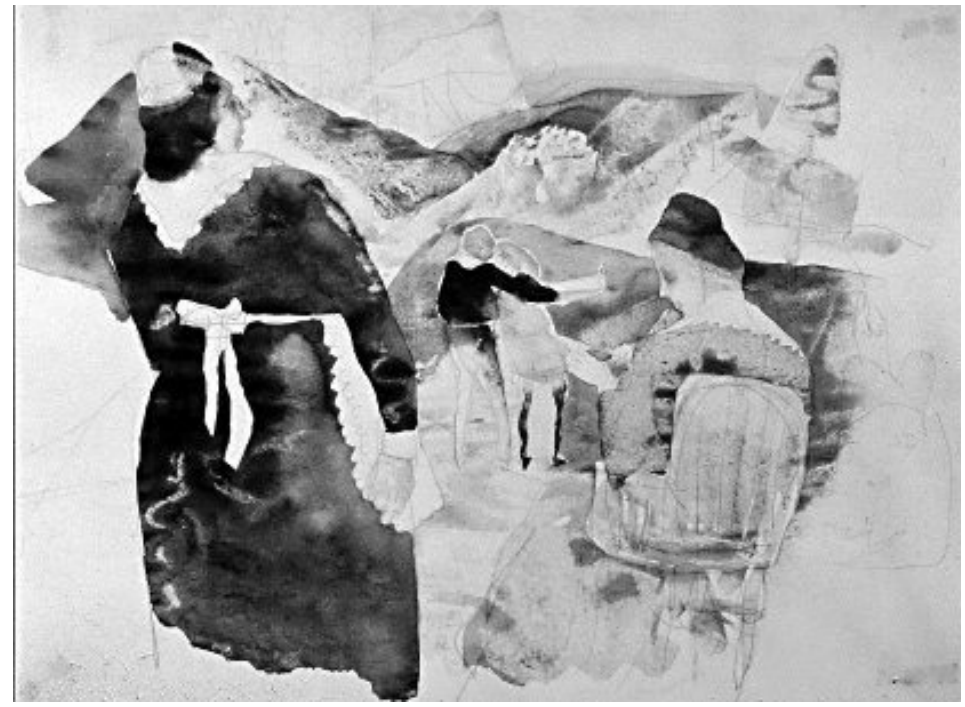

(Fig. 4) "The governess, Mrs. Grose and the children". Philadelphia Museum of Art. 


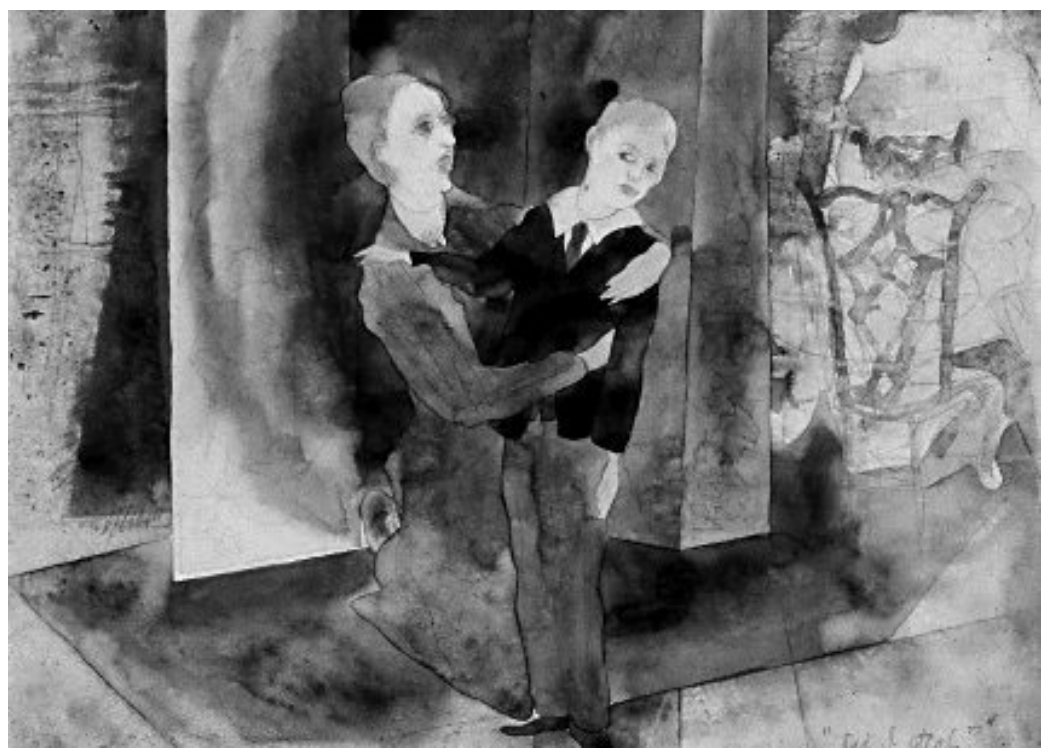

(Fig. 5) “Did I steal?” Philadelphia Museum of Art. 